\title{
A CULTURA DOS DIREITOS CULTURAIS ${ }^{1}$
}

\section{THE CULTURE OF THE CULTURAL RIGHTS}

Joerg Luther ${ }^{2}$

Resumo: O ensaio inicia com uma revisão das incertezas que permeiam o conceito de "direitos culturais", questão que é fortemente ligada à indeterminação do próprio conceito de "cultura". Realiza-se um estudo comparativo filológico sobre o conceito de cultura no sentido do que é relevante quanto à universalidade dos direitos culturais. O artigo enfoca na análise do conceito de "cultura legal de culturas", da obra de Peter Häberle, que é necessário para o estudo do papel dos direitos culturais no constitucionalismo contemporâneo. Analisa-se a origem dos direitos culturais, através de uma revisão das legislações, que frequentemente são fragmentadas e podem estar sujeitas a interpretações sistemáticas e evolutivas. Em seguida, prossegue-se com a análise das garantias legais de proteção aos direitos culturais no estado da arte. O ensaio termina com a exposição de alguns dos desafios futuros que definirão o debate sobre a lei e a cultura dos direitos fundamentais culturais.

Palavras-chave: Direitos culturais. Cultura. Direitos fundamentais.

Abstract: The essay opens with a review of the uncertainties in the definition of the concept of "cultural rights", which is strongly connected with the undeterminedness of the concept of "culture" itself. The A. performs a philological comparative study on the concept of culture in the meaning that is relevant with regard to the universality of cultural rights. The essay then focuses on the analysis of the concept of "legal culture of cultures" in the work of Peter Häberle, which is necessary for the study of the role of cultural rights in contemporary constitutionalism. The A. analyses the origins of cultural rights, through a review of the relevant sources of the law, which are often fragmented, and that could be subject to systematic and evolutive interpretation. The A. then proceeds with the analysis of the legal guarantees of safeguard of cultural rights in the state of the art. The essay closes with the exposition of some of the forthcoming challenges that will define the debate on the fundamental cultural rights' law and culture.

Keywords: Cultural rights. Culture. Fundamental rights.

Recebido em 6 de fevereiro de 2020

Aceito em 20 de outubro de 2020

\section{Direitos culturais como fragmentos de uma "cultura de culturas"}

O que se entende por "cultura" quando se refere a direitos culturais? A resposta é complicada, porque a maioria dos juristas usa o conceito sem intenção ou sem poder defini-lo. As incertezas

\footnotetext{
Traduzido por Gabriele Ana Paula Danielli Schmitz; Mestre e doutoranda em Direito pelo Programa de Pós-graduação em Direito da Universidade do Oeste de Santa Catarina; Professora na Universidade do Oeste de Santa Catarina; Rua Oscar Ervino Keil, 443, 89870-000, Bairro Bela Vista, Pinhalzinho, Santa Catarina; Brasil; https://orcid.org/0000-0002-1376-2368; gabriele27264@gmail.com

2 In memorian. Doutor em Direito Constitucional pela Universitá Estatale de Milano, Itália. Foi Professor titular de instituições de direito público na Universidade do Piemonte Oriental. Foi Professor associado da Faculdade de Direito da Universidade de Pisa. A partir de 2010, realizava cursos também na Universidade de Turim. Entre 2011 e 2013 foi o primeiro coordenador do $\mathrm{PhD}$ em Autoridades Locais, Serviços Públicos Locais e Direitos da Cidadania (DRASD) até 2013, depois coordenador do novo $\mathrm{PhD}$ em Instituições Públicas, Sociais e Culturais na Universidade do Piemonte Oriental. Autor e editor de numerosas publicações científicas no campo do direito constitucional e público, incluindo Il futuro della Costituzione, com Gustavo Zagrebelsky e Pier Paolo Portinaro, Einaudi, 1996; Esperienze di giustizia costituzionale, com R. Romboli e R. Tarchi, Giappichelli, 2000; I primpi fondamentali della Costituzione Italiana, A world of Second Chambers, Giuffré 2006; Europa constituenda, Giappichelli 2007; Documentos constitucionais da Itália e Malta, De Gruyter, 2010.
} 
conceituais que derivam desse costume generalizado colidem com uma norma convencional das ciências jurídicas que exige a busca de conceitos de segurança jurídica. O gato que morde o rabo. Se cada definição é o resultado de uma ideia e cada ideia faz parte de uma cultura e se os costumes ou convenções que a definem fazem parte da cultura de juristas, especialmente acadêmicos, a falta de definição pode ser sentida como uma falta e um déficit de cultura, mas também pode ser explicado como uma auto-referência e circularidade inevitáveis de qualquer raciocínio sobre a cultura. Como as filosofias e histórias da cultura, os discursos dos juristas sobre cultura são apenas parte dela ou, se você preferir, um dos muitos fragmentos que compõem a "cultura das culturas" hoje.

$\mathrm{Na}$ busca de um conceito de cultura, as ciências jurídicas, como ciências políticas, econômicas e sociais e humanas, incluindo a antropologia cultural, concentraram-se em diferentes tempos e lugares, em diferentes aspectos: práticas e obras de elevação espiritual do homem em direção à beleza e à bondade, um conjunto de sabedoria, crenças e modos de vida através dos quais um povo ou uma sociedade se distingue dos outros, um sistema institucional parcial da sociedade que produz interpretações estéticas e intelectuais do mundo, um conjunto de discursos e sistemas simbólicos que refletem ideias, pensamentos, paixões, valores e significados. ${ }^{3} \mathrm{~A}$ "cultura" é declinada no plural e não é eterna ou onipresente, porque tem uma história com aspectos estáticos e dinâmicos, uma geografia com mapas que mostram circulações maiores e menores. Ela não possui apenas uma, mas talvez ainda mais vidas ou ciclos de vida e é objeto do estudo de uma pluralidade de ciências humanísticas e sociais, jurídicas e políticas, sociológicas e econômicas, fragmentadas por objetos e integradas por teorias e ciências culturais que ainda não são interdisciplinares o suficiente. Teorias e ciências culturais participaram nesta vida em fases da construção moderna, de desconstrução pósmoderna através de conceitos como identidades parciais, híbridos, crioulos, sincretismos, bricolage, etc. e, finalmente, de reconstrução mais ou menos romântica através de redescobertas e novas reconstruções da cultura popular, memória, patrimônio cultural, multi e interculturalidade, etc. ${ }^{4}$

Se as ciências jurídicas são apenas um fragmento da "cultura das culturas", nem mesmo o jurista pode escapar dos contextos histórico e geográfico de seu conhecimento. Perguntar sobre a "cultura dos direitos culturais" significa enfrentar uma questão que também é relevante para o entendimento da cultura jurídica, isto é, para a interpretação das regras que legitimam a pesquisa e os fatos e percepções reais que determinam a identidade cultural das ciências jurídicas. Este não é um tópico novo 5 e não será possível dar uma resposta exaustiva neste ensaio, mas sim observações

\footnotetext{
3 Cfr. a tipologia de A. Reckwitz, Die Kontingenzperspektive der 'Kultur'. Kulturbegriffe, Kulturtheorien und das kulturwissenschaftliche Forschungsprogramm ", em: F. Jaeger / J. Rüsen (eds.), Handbuch Kulturwissenschaften, Stuttgart 2004, v. 3, p. 1-20.

4 Uma primeira abordagem é oferecida em W. Leimberger, Kultur und Kulturtheorien: Zwischen De- und Rekonstruktionen, Schweizerische Akademie der Geistes- und Sozialwissenschaften, Berna, 2014.

5 Também no próprio trabalho do autor, $c f$. J. Luther, O painel dos filósofos e dentistas dos diretores culturais: diritti culturali fondamentali?, Political theory 2001, 177 e segs.; Le frontiere dei diritti culturali in Europa, em: G. Zagrebelsky (a cura di), Diritti and Costituzione nell'Unione Europea, Rome 2003, 221 and segs; Il diritto alla memória do diretivo cultural dell'uomo in democrazia, em: Studi in onore di F. Modugno, Napoli 2011, III, 2091 e segs.
} 
preliminares que ajudam no desenvolvimento da pesquisa. $O$ que os juristas sabem sobre direitos culturais e como o estudo dos direitos culturais permite compreender melhor essa palavra "cultura"?

Os direitos culturais são apenas parte dos direitos fundamentais, considerados, com ou sem razão, "uma cindarella fracassada do léxico internacional dos direitos humanos" e sua parte mais fraca ou "soft", mesmo no momento em que os críticos veriam como a "era dos direitos" desejada por Norberto Bobbio chegou a um fim desconsolado.' Sua pluralidade reflete a pluralidade de ideias e teorias sobre cultura apresentadas acima, mas também poderia ser o resultado de uma dialética específica dos próprios direitos fundamentais, dificilmente sintetizável em um único "direito à cultura".

A cultura dos direitos culturais pode significar tanto o conceito quanto o modelo teórico de cultura designado por esses direitos e as práticas adequadas para garanti-los. Antes de tudo, aqui propõe-se prestar atenção especial a alguns estudos de filologia comparada sobre o conceito de cultura, relevantes para a universalidade dos direitos culturais. (\$2) Em segundo lugar, é oferecida uma reconstrução da "cultura jurídica das culturas" na obra de Peter Häberle, o primeiro a usar ciências culturais no Direito Constitucional, a fim de avaliar o papel dos direitos culturais no constitucionalismo atual. (\$3) Em um terceiro passo, tentamos reconstruir sua invenção (\$4) e os motivos que podem orientar uma interpretação sistemática e evolutiva de suas fontes legais fragmentárias ( $\int 5$ ). Posteriormente, serão analisados os instrumentos e as garantias legais dessa categoria de direitos, ou seja, o que caracteriza sua cultura jurídica até então percebida como "arte pobre" (\$ 6). As conclusões identificarão uma série de desafios para o futuro do Direito e a cultura dos direitos culturais fundamentais (\$ 7$)$.

\section{A etimologia e a tradução universal incerta da palavra}

Merriam-Webster indicaram que "cultura" foi a palavra mais pesquisada do ano de $2014 .{ }^{8}$ No entanto, quantidade nem sempre é qualidade e a situação nem sempre é um indicador de cultura. Para reconstruir seu significado, é necessário retornar à filologia, a ciência cultural, talvez mais próxima da jurisprudência e da história da palavra.

As origens latinas da "cultura animi" (Cícero) e os pseudogriegos da "georgica animi" (Bacon) indicam uma origem "clássica" e europeia, também cristã (culto). ${ }^{9}$ Os contrastes modernos entre "Kultur" e "Natur" ou "cultura" (em inglês também verbo ${ }^{10}$ ), "civilização" revelam uma

\footnotetext{
6 D. McGoldrick, Cultura, Culturas e Direitos Culturais, em: M. Baderin, R McCorquodale (eds.), Direitos econômicos, sociais e culturais em ação, Oxford University Press 2007, p. 447.

7 N. Bobbio, L'età dei diritti, Torino 1990; G. Zagrebelsky, Diritti per forza, Torino, 2017.

8 J. Rothman, O significado de 'cultura', New Yorker 26. 12. 2014. Disponível em: https://www.newyorker.com/books/ joshua-rothman/meaning-culture.

9 O título de A. Assmann à obra póstuma de J. Taubes, Vom Kult zur Kultur, Munique 1996, trad. English: Do culto à cultura: fragmentos para uma crítica da razão histórica, Stanford University Press, 2010.

${ }^{10}$ Cfr. I. Kant, Idee zu einer allgemeinen Geschichte in weltbürgerlicher Absicht, 1784: Nós trabalhamos com eles Grade durch Kunst und Wissenschaft kultiviert. veja o que há de mais moderno em termos de cultura; o Gebrauch está mais
} 
dialética que é projetada tanto no subjetivo, na identidade cultural do homem que se relaciona consigo mesmo e com os demais, quanto ao objetivo, nos bens e serviços produzidos por diferentes instituições. No entanto, os vínculos histórico-filológicos entre "colere" e "colônia" também não devem ser ignorados. Nesse sentido, surge um primeiro problema de natureza crítica sobre a genealogia do termo "cultura", sobre suas ambigüidades e, em particular, sobre suas conotações biológicas e territoriais e sobre sua potencial função hegemônica. Não existe o risco de a palavra também transmitir - organismos perigosos como racismo, organismo, fundamentalismo, eurocentrismo, ocidentalismo e imperialismo cultural?

Nesse sentido, em auxílio da filologia comparada, observou-se que o conceito não é universal, pois em idiomas não europeus existem traduções que contêm até conceitos múltiplos, enquadrados em contextos ideológicos altamente diversificados. ${ }^{11}$ Em japonês, a palavra bunka é escrita com ideogramas chineses 文化, onde 文 significa proposição ou escrita, 化 mudança ou devir r. O conjunto originalmente designou uma era do governo imperial, a partir do momento em que Meiji se tornaria o equivalente à noção alemã e europeia. A recepção também é destacada pelas letras para o equivalente a "civilização", que adiciona ao símbolo de escrita um segundo símbolo que significa lúmen文明. ${ }^{12} \mathrm{O}$ conceito chinês de wenhua correspondente a 0 foi recentemente interpretado como o equivalente a "ser humano", carregado com expectativas de harmonia com a natureza exterior e interior. ${ }^{13}$ Mesmo na Índia, uma das maneiras de traduzir a cultura é precisamente "sânscrito", outra "Sabhyata" parece significar mais elevação e formação (civilização). ${ }^{14}$

Em árabe, distinguimos entre "Thaqâfa" e "Hadâra", a primeira derivada do verbo "thaqifa" (encontre, agarre, seja capaz, sábio), o segundo do verbo "hadara" (esteja presente, participe, sedentário), ambos os aspectos de "Madaniyya", derivado do substantivo "Madîna" (cidade). ${ }^{15}$ A tradução para línguas africanas tornou-se ainda mais difícil desde a pesquisa de Frobenius, em 1898, sobre a origem das culturas africanas negligenciadas. A palavra suaíli "utamaduni" parece derivar do

próximo, o soldador no das Sittenähnliche in der Ehrliebe und der äußeren Anständigkeit hinausläuft, macht bloß die Zivilis. Disponível em: https://korpora.zim.uni-duisburg-essen.de/Kant/aa08/026.html.

${ }^{11} \mathrm{~J}$. Bolten, Kultmt Kultmt von colere: Ein Plädoyer für einen holistischen, nicht linear linear Kulturbegriff, in: E Jammal, Elias (Hg.): Cultural and Interkulturalität, Wiesbaden 2014, 85-108.

${ }^{12}$ N (aoji) Kimura, Kulturbegriff in japanischer Sprache (2000), em: Enzyklopädie vielsprachiger Kulturwissenschaften. Disponível em: http://www.inst.at/ausstellung/enzy/kultur/japan_kimura.htm.

${ }^{13}$ Fei Deng \& Jianli Tang, 'Introduzir a não simetria da derivação de palavras entre' Wenhua 'e' Cultura ', International Journal of Linguistics and Communication, junho de 2015, 145-150: "Wen' significa 'sentir e experimentar a natureza de cor e, em seguida, pintando e descrevendo coisas, finalmente, é possível obter conhecimentos correlatos através desse processo na língua chinesa antiga'. 'Hua' significa 'mudar', que enfatiza que as pessoas podem melhorá-las com base em 'Wen'. O ponto de partida dos significados enfatiza a relação harmoniosa entre os seres humanos e a natureza exterior e enfatiza a harmonia interior dos seres humanos por si mesmos." Sobre o uso do wenhua na legislação sobre patrimônio cultural hoje, S. Novaretti, "Oue tal servir o presente": giuridica dei beni culturali e partecipazione pubblica nella RPC, Napoli 2017, p. 72ss.

${ }^{14}$ Agradecemos ao Prof. Prasananshu, Universidade Nacional de Direito, Nova Délhi.

${ }^{15}$ S (amira) Kortantamer, Der Begriff "Kultur" im Arabischen (2001), em: Enzyklopädie vielsprachiger Kulturwissenschaften. Disponível em: http://www.inst.at/ausstellung/enzy/kultur/arabisch_kortantamer.htm. 
árabe e "kustaarabika", incluindo o árabe no conceito de civilização. ${ }^{16}$ Nas línguas bantus do sul, seria feita referência ao conceito de "ubuntu", compaixão humana, incluindo também ancestrais e seu culto.

No contexto do debate sobre universalismo e relativismo dos direitos humanos, essas referências às diferenças filológicas podem ser suficientes para destacar, primeiro, como o próprio conceito de cultura é o artefato de uma linguagem histórica europeia que conquistou as linguagens veiculares da globalização. Mesmo as ciências culturais ainda não são capazes de "traduzir" essa palavra para todas as línguas do mundo, nem atualmente é possível prever a produção, por inteligência artificial e algoritmo, de uma linguagem perfeitamente compreensível para toda a humanidade. ${ }^{17}$ Embora a palavra não é e não será universal, isso não significa que o efeito Babel seja inevitável e que um ou mais conceitos não possam ser encontrados como traduções mais ou menos equivalentes em todas as línguas e que os europeus não possam aprender com os não europeus.

De qualquer forma, surgirá um problema prático: żas traduções da mesma palavra "cultura" servem para proteger ou ameaçar ainda mais os idiomas das minorias, em particular os "idiomas ameaçados" aos quais se dedica o Ano do Línguas indígenas? O Artigo 14 da Declaração das Nações Unidas sobre os Direitos dos Povos Indígenas de 2007 compromete os Estados "em conjunto com os povos indígenas" a garantir seu acesso, mesmo que morem fora de suas próprias comunidades, à educação em sua própria cultura e em seu próprio idioma. A proteção de idiomas que não conhecem a palavra cultura requer serviços de tradução e mediação e pode envolver custos de comunicação mesmo para culturas que não possuem uma palavra equivalente.

Outros problemas práticos surgem do fato de que a palavra também pode ser usada para fins prescritivos e exortativos, direcionados a ordens e persuasões, especialmente se considerarmos que a cultura é um bem e um valor em si. Essas funções estão sempre sujeitas ao perigo de abuso, principalmente se estiverem ligadas aos ismos e ideologias indicados acima e se refletem bem nas controvérsias sobre o conceito de "Leitkultur", que pode ser traduzido mais como uma cultura (espiritual) orientadora que como uma cultura hegemônica (coercitiva). Sabemos que, em nome da cultura, você pode fazer política e fazer negócios, mas também pode estabelecer limites para ambos e nutrir uma "resiliência" do pluralismo contra a homogeneidade, pelo menos através da memória da diversidade. Além de razões frias, a cultura também é uma palavra de paixão, às vezes mais quente, às vezes mais morna, que não pode ser usada apenas por demagogos e especuladores, mas também pode guiar o desejo de enriquecimento individual, o prazer em desfrutar de formas de vida coletiva e "glória" na ação de órgãos públicos.

No debate entre antropólogos, são principalmente os autores alemães que querem defender o conceito, opondo-se em particular aos autores americanos. ${ }^{18}$ Bolten volta às raízes

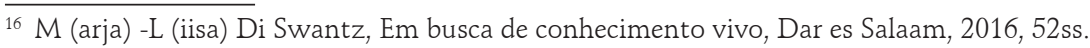

17 U. Eco, La ricerca della lingua perfetta nella European culture, Roma-Bari, Laterza, 1993.

${ }^{18}$ Cfr. Além da contribuição de J. Bolten, a conversa com Lila Abu-Lughod em C. Brumann, Redação para a cultura: por que um conceito de sucesso não deve ser descartado, em: Current Anthropology, v. 40, p. 1-27, 1999. Edição especial: Cultura - Uma Segunda Chance?
} 
etimológicas para sustentar que o denominador menos comum da cultura em termos de "colere" é o cuidado das relações do homem com o ambiente natural, o ambiente social (in loco), consigo mesmo (imanência) e com as divindades (transcendência). ${ }^{19}$ Se se reconhece a polissemia da palavra, a ambiguidade residual deixa de justificar seu abandono, o abuso não impõe a falta de uso. Descartar o conceito significaria perder suas interpretações idealistas e realistas, recompensando o niilismo da desconstrução em escala mundial e renunciando ao seu potencial valor de reconstrução. $\bigcirc$ abandono da busca pelos significados de "cultura" poderia não apenas ser contraproducente no combate aos ismos diabólicos, mas também ser impossível de fato e de direito, justamente pelo reconhecimento dos direitos culturais como direitos humanos invioláveis.

\section{0 desenvolvimento gradual de uma "cultura legal de culturas" nas obras de Peter Häberle}

A teoria jurídica talvez de uma maior abertura às ciências da cultura se deve às obras de Peter Häberle. Na primeira edição da "doutrina da constituição como ciência da cultura" (1982), ele observou a vergonha e as tentativas da nova "antropologia cultural" de desenhar mapas de aplicação do conceito para encontrar uma síntese. A obra distinguiu um conceito tradicional e elitista de ciências jurídicas, composto pela tríade de instituições de ensino / formação (Bildung), ciência e arte, e um conceito mais amplo e aberto: cultura em sentido amplo constituiria o "contexto de todos textos legais". ${ }^{20}$ A cultura, em sentido amplo, era uma espécie de denominador médio comum das centenas de definições antropológicas e sociológicas que se referem à história (patrimônio e tradição), normas (e valores), mentalidade (e aprendizado), estruturas processuais e organizacionais ou os bens gerados (materiais, ideais, símbolos), acrescentando imediatamente que esse "quadro material-sistemático" seria apenas parcial e não seria imediatamente utilizável pelo jurista. A síntese jurídica do todo foi realizada por uma tríade de "pontos de orientação" que poderiam ser traduzidos em valores ou princípios jurídicos, uma espécie de "cultura jurídica da cultura": o dever de preservar tradições, a liberdade de inovação transformadora e pluralismo de sujeitos e instituições culturais. ${ }^{21}$

O trabalho preparatório "Do estado da cultura ao Direito Constitucional da Cultura" (1981) mostrou como o conceito mais amplo levou a uma crítica aos clichês tradicionais de "Kulturstaat", utilizado internamente como "Estado que administra a política cultural" e externamente como um mandato para dominar o "estado bárbaro". Häberle abriu a cultura jurídica às ideias de uma "cultura

\footnotetext{
${ }_{19}$ Op. Cit. 9.

${ }^{20}$ Verfassungslehre als Kulturwissenschaft, Berlim 1982, 10ss. A síntese do debate em antropologia cultural foi confirmada internacionalmente, por exemplo, por E. Vermeersch, Uma análise do conceito de cultura, em: B. Bernardi (a cura di) O Conceito e a Dinâmica da Cultura, Haia, Mouton 1977.

${ }^{21}$ Op. Cit., 4.
} 
para todos e por todos" de culturas populares, alternativas e "inferiores", não sem uma parcela mínima de críticas à ideia de cultura do ócio da burguesia. ${ }^{22}$

A referência às ciências da cultura não se limitou a refletir o espírito da época, mas a seguir uma tradição particular da ciência constitucional alemã e os vínculos com a Kulturphilososophie destacados nas teorias de Radbruch, Heller e Smend.

Häberle não mencionou, mas insistindo no pluralismo criticou implicitamente a tentativa de definir o Bundesverfassungsgericht que em 1959 já havia rejeitado os apelos dos Länder de BadenWürttemberg, Hessen e Niedersachsen (Baixa Saxônia) contra a nacionalização do patrimônio cultural da Prússia. Nessa decisão, os juízes de Karlsruhe confiavam na imagem de uma constituição material para definir como cultura "o conjunto (Gesamtheit) de forças espirituais efetivas dentro de uma comunidade", ${ }^{23}$ rejeitando explicitamente a ideia mais liberal de que tais forças devem necessariamente se desenvolver "em formas independentes do Estado, tendo em si o seu próprio valor." 24

A segunda edição da doutrina häberliana (1998) também explicou em uma nota o contexto internacional da primeira edição, em particular a segunda Conferência Mundial da UNESCO de 1982, cuja declaração final promoveu uma nova "política cultural que preserva a identidade nacional de cada povo e ajuda a enriquecê-la ", apagando os traços do colonialismo e inspirando o trabalho em prol de um estado constitucional cooperativo."25

Em seu relatório de 1984 aos advogados públicos de língua alemã sobre o mandato cultural do Estado (Kulturauftrag), Udo Steiner distinguiu um amplo conceito sociológico (síntese de modos de vida, posições de valores e modos de dirigir uma sociedade) de um conceito jurídico em sentido estrito, um "conceito de conteúdo convencional para certos campos de atividade espiritual e criativa (educação, ciência, arte, religião) em relações especiais (diferenciadas) com o Estado". Em alguns contextos administrativos, a cultura indicaria inclusive um conjunto de instituições diferentes e residuais de educação, ciência, arte e religião. ${ }^{26} \mathrm{O}$ conceito delineado por Dieter Grimm - novamente em Bielefeld - caracterizou a cultura desse tipo como um sistema que, diferentemente de outros sistemas, se referia a objetos espirituais que deveriam ser criados ou descobertos, tendo como função a "reprodução ideal da sociedade", isto é, a interpretação do mundo (Weltdeutung), a produção de significado (Sinnstiftung), o fundamento, a tradição e a crítica de valores", incluindo as chamadas culturas e subculturas opostas." 27

\footnotetext{
${ }^{22}$ Vom Kulturstaat zum Kulturverfassungsrecht, em: P. Häberle (a cura di) Kulturstaatlichkeit und Kulturverfassungsrecht (1981), Darmstadt 1982, 30ss.

23 "Gesamtheit der innerhalb einer Gemeinschaft wirksamen geistigen Kräfte". Cfr. também a reconstrução da jurisprudência em M. Naucke, Der Kulturbegriff in der Rechtsprechung des Bundesverfassungsgerichts, Hamburgo 2000.

${ }^{24}$ Finalmente, BVerfG, Urteil des Zweiten Senats vom 28. Januar 2014 - 2 BvR 1561/12 -

Disponível em: http://www.bverfg.de/e/rs20140128_2bvr156112.html = BVerfGE 135, 155-234, Rn. 104.

${ }^{25}$ Verfassungslehre als Kulturwissenschaft, 2. ed. Berin 1998, 5, nota 8.

${ }^{26}$ U. Steiner, Kulturauftrag des Staates, em: Veröffentlichungen der Vereinigung der Deutschen Staatsrechtslehrer (VVDStRL) 42. 1984, 8ss

${ }^{27}$ D. Grimm, Kulturauftrag des Staates, VVDStRL 42. 1984, 60ss.: "A cultura custa não apenas o meio vital (Lebenswelt) do indivíduo, mas cria uma espécie de identificação coletiva." (62).
} 
No debate da época, Walter Leisner confessou com mais ceticismo um conceito global de cultura e Josef Isensee lançou talvez o ataque mais feroz:

A cultura não distingue e não prejudica ninguém. Todos podem imaginar algo diferente, mas todos pensam em algo agradável. A palavra pode ter significados diferentes, como mostram os relatórios e o debate: abrangente ou setorial, despretensioso ou cheio de pretensões, igualitário ou elitista, sub ou super, estético, político ou social - da cornucópia da palavra flui tudo o que é necessário no momento: "Cultura" não é um conceito jurídico. Não é um conceito que se refira à palavra e ao significado, mas uma palavra à qual são atribuídos conceitos heterogêneos. ${ }^{28}$

Peter Häberle respondeu que a cultura não pode ser excluída do Direito Constitucional para recuperá-la mais adiante na teoria geral do estado, uma vez que um uso diferenciado do conceito também pode ser feito em trabalhos jurídicos. ${ }^{29}$

A oposição do Isensee teve um significado político preciso, a saber, a rejeição de propostas de emenda à Lei Fundamental que visavam legitimar a ação cultural das autoridades públicas federais seguindo o modelo da Kulturstaatsklausel de Constituição da Baviera (art. 3 construídos 1945). Nesse sentido, o modelo preferível para Isensee parecia ser o da Áustria católica, para cuja Constituição a palavra "cultura" permaneceu estranha. Na segunda edição de 1998, Häberle finalmente optou por uma posição federalista intermediária, propondo integrar essa cláusula apenas na norma que exige a homogeneidade das constituições regionais para otimizar os poderes dos Länder. Essa conseqüência legal da "concepção aberta de cultura" foi aceita pela Constituição Suíça de 1999, que dedicou uma seção inteira a "educação, pesquisa e cultura", com uma provisão específica de objetivos e competências (art. 69).

Na primeira edição da doutrina de Häberle, a "lei constitucional da cultura" era uma lei objetiva com seu próprio sistema e técnicas de sistematização, mas não podia e não deveria reivindicar "jurificar" toda a cultura. O sistema que podia ser chamado de "cultura legal da cultura" deve permanecer sendo um "fragmento" a ser interpretado à luz de seus próprios contextos culturais. ${ }^{30}$ Era composto de cláusulas de "Estado da cultura", objetivos de valor educativo e fórmulas de juramento, catálogos de competências e direitos fundamentais específicos, bem como garantias das festividades, ${ }^{31}$ elementos aos quais a segunda edição de 1998 acrescentou cláusulas para a proteção do patrimônio e da identidade cultural, artigos sobre idiomas e princípios do pluralismo cultural e

\footnotetext{
${ }_{28}$ VVDStRL 42. 1984, 133.

29 VVDStRL 42. 1984, 138.

${ }^{30}$ P. Häberle, Verfassungslehre ${ }^{1}$ cit., 78. Cf. A. Vosskuhle, T. Wischmeyer, Der Jurist im Kontext, in: R. v. Ooyen, M. Möllers (Hg.), Cultura Verfassung, Baden-Baden 2016, 39ss (trad. It JL), Il giurista nel contesto, Lo Stato 2018, 163ss.

${ }^{31}$ Cf. Feiertagsgarantien als kulturelle Identitätselemente des Verfassungsstaates, Berlim 1987; Der Sonntag als Verfassungsprizip, Berlim, 1988.
} 
"direitos culturais fundamentais" (kulturelle Grundrechte). ${ }^{32}$ Nesse sentido, ele citou as constituições latino-americanas do Peru ( art. 21 e segs.), Guatemala (art. 57 e segs.) e Brasil (art. 215) como exemplos de novas garantias e aplicação dos artigos 27 da DUDH e 15 do Pacto Internacional sobre Direitos Econômicos, Sociais e Culturais. ${ }^{33}$

Essas garantias constitucionais e internacionais dos direitos culturais fundamentais nos países em desenvolvimento eram novos textos no paradigma do desenvolvimento gradual de textos constitucionais que se somavam aos direitos civis e políticos da liberdade declarados fundamentais nas constituições europeias do século XX, integrados na Convenção Europeia dos Direitos do Homem e na Carta Social Europeia, um direito constitucional europeu comum à busca de princípios e normas comuns nos domínios da liberdade de religião, arte e ciência, direitos educacionais dos pais, etc. Ele não questionou seu conteúdo essencial (1962), mas aplicou a teoria da dupla dimensão, subjetiva e objetiva-institucional, combinando "liberdades culturais" com as reivindicações de benefícios do Estado social (1971).

Essas garantias constitucionais e internacionais dos direitos culturais fundamentais nos países em desenvolvimento eram novos textos no paradigma do desenvolvimento gradual de textos constitucionais que se somavam aos direitos civis e políticos da liberdade declarados fundamentais nas constituições europeias do século XX, integrados na Convenção Europeia dos Direitos Humanos e na Carta Social Europeia, um direito constitucional europeu comum à busca de princípios e normas comuns nos campos da liberdade de religião, arte e ciência, direitos educacionais dos pais, etc. Ele não questionou seu conteúdo essencial (1962), mas aplicou a teoria da dupla dimensão, subjetiva e objetivo-institucional, combinando "liberdades culturais" com as reivindicações de benefícios próprios do Estado social (1971).

A doutrina "culturalista" foi aplicada por seu autor, acima de tudo, à análise da Constituição Cultural da Europa (1983), ${ }^{34}$ enquanto o contexto cultural dos direitos fundamentais se aprofundou sobretudo na dimensão do "tempo" (1983). Seguiram outros estudos comparativos e universais sobre políticas (e direitos) de família (1984), sobre os conteúdos culturais do direito à dignidade humana (1988), sobre problemas linguísticos (e os direitos correspondentes) (1990), sobre liberdade of art (1992), sobre esporte (1993) e, finalmente, sobre um "possível" (- meta) "direito à cultura" sintético (Recht auf Kultur), ${ }^{35}$ com conteúdos diferenciados por dimensões e áreas institucionais (1994) .

\footnotetext{
32 P. Häberle, Verfassungslehre ${ }^{2}$ cit., 16ss. Uma primeira referência aos direitos culturais fundamentais pode ser encontrada em: Kulturverfassungsrecht im Bundesstaat, Viena 1980, 46 e s. Sobre a garantia dos direitos culturais fundamentais como "guardiões da liberdade cultural", P. Häberle, Europa in kulturverfassungsrechtlicher Perspektive, Jahrbuch des öffentlichen Rechts 1983, 24ss.

${ }^{33}$ Texto subsequentemente integrado em: Der kooperative Verfassungsstaat aus Kultur und als Kultur, Berlin 2013, 434ss.

${ }^{34}$ Europe in kulturverfassungsrechtlicher Perspektive (1983), em: Rechtsvergleichung im Kraftfeld des Verfassungsstaates 1992, 45ss.

35 Schlußanmerkung, in: T. Fleiner-Gerster (a cura di), Die multikulturelle und multiethnische Gesellschaft, Fribourg 1995, 37 ss.
} 
Posteriormente, os estudos häberlianos se centraram em alguns problemas cruciais da cultura do ponto de vista do Direito Constitucional, começando pelos relacionados ao fundamentalismo e à verdade (1995). No trabalho sobre a proteção da propriedade cultural, a cultura foi apresentada como um quarto elemento transformador do Estado constitucional na comunidade mundial da humanidade unida pelos direitos humanos, mas o patrimônio cultural nacional e internacional "produzido" pelo exercício dos direitos e o cumprimento dos deveres culturais fundamentais parece não ser capaz de unir as diferentes gerações e categorias de direitos (1996). ${ }^{36} \mathrm{O}$ trabalho sobre as relações entre o Estado e a Igreja na Europa acentuou as dimensões coletivas e corporativas da liberdade religiosa (2000). ${ }^{37}$

Uma coleção de ensaios traduzidos para o italiano em 2003 foi intitulada "a cultura dos direitos e os direitos da cultura", mas na dialética entre a cultura legal dos direitos fundamentais e a autonomia das instituições culturais, os direitos culturais permanecem apenas em segundo plano. ${ }^{38}$ Diante das reivindicações de um "direito à identidade cultural", ele insiste mais na natureza fragmentária dos discursos jurídicos sobre identidades coletivas e em questões de referência específicas (Bezugsfragen) delas (2005). ${ }^{39}$ Em trabalhos recentes sobre hinos nacionais (2006), bandeiras (2007), bens culturais comemorativos (2011), aspectos institucionais prevalecem. Na elaboração de uma doutrina universal da constituição do "Estado Constitucional Cooperativo" (2013), a "culturalidade" das liberdades que têm cultura por objeto e tarefa, mas também na necessária integração entre o "status mundialis hominis""os direitos de cidadania do"status civilis vel culturalis" nos direitos fundamentais. ${ }^{40}$ Finalmente, um dever fundamental de paz também deve estar associado a esses direitos fundamentais (Friedensgebot) (2017). ${ }^{41}$

À luz desses textos, percebe-se que a "cultura jurídica da cultura" continua a desempenhar um papel central no constitucionalismo, entendido como o pensamento sobre as virtudes do estado constitucional. A teoria de Häberliana defende a liberdade cultural, mas não nega a realidade dos conflitos culturais, nem os velhos e novos perigos do empobrecimento. $O$ desenvolvimento dessa cultura exige a preservação das tradições e a inovação das criações, o pluralismo de autonomias e a pluralidade de direitos culturais fundamentais.

\footnotetext{
${ }^{36}$ National-verfassungsstaatlicher und universaler Kulturgüterschutz, em: F. Fechner, T. Oppermann, L. Prott (eds.), Prinzipien des Kulturgüterschutzes, Berlin 1996,

${ }^{37}$ Das Verhältnis von Staat e Kirche im werdenden Europe, em: P. Häberle, JP Müller (a cura di), Menschenrechte und Bürgerrechte in einer vielgestaltigen Welt, Fribourg 2000, 85ss.

38 A cultura dos diretos e diretos da cultura, Milão, 2003.

${ }^{39}$ Cfr. também P. Häberle, Costituzione e identità culturale. Tra Europa e Stati National, Milano 2006.

${ }^{40}$ Der kooperative Verfassungsstaat - aus Kultur und als Kultur, Berlin 2013, 354ff.

${ }^{41}$ Die Kultur des Friedens - Thema einer universalen Verfassungslehre, Berlin 2017, 175ss.
} 


\section{A invenção dos direitos culturais fundamentais}

Direitos culturais fundamentais são direitos que remontam a um conceito jurídico de cultura que tende a ser mais restrito no Direito Constitucional e mais amplo no Direito Internacional. O adjetivo "cultural" indica, primeiro, uma categoria específica de direitos humanos, extraída da estrutura e sistema geral da Declaração Universal dos Direitos Humanos de 1948 (DUDH), que primeiro identifica direitos civis e políticos e acrescenta então, o direito de

toda pessoa, como membro da sociedade, à seguridade social [...], bem como à satisfação, mediante esforço nacional e cooperação internacional, levando em consideração a organização e os recursos de cada Estado, dos direitos econômicos, sociais e culturais indispensáveis à dignidade de cada um deles e ao livre desenvolvimento de sua personalidade (art. 22).

Embora essa estrutura não forneça uma hierarquia de direitos, é necessário sublinhar:

a) que os direitos culturais são direitos que afetam a integração social das pessoas;

b) pressupõem seguridade social, dignidade e desenvolvimento livre da personalidade;

c) que somente são fundamentais os direitos culturais indispensáveis para a dignidade e o desenvolvimento da personalidade;

d) que sua garantia é competência das nações e da cooperação internacional.

Ao especificar os direitos culturais fundamentais, a UDH qualifica como "cultural" tanto o direito à educação (art. 26), de alguma forma funcional para a restauração da "civilização", como o direito de "participar livremente da vida cultural" da comunidade" (art. 27).

Se você voltar às origens dessa declaração, o primeiro rascunho do Drafting Committee da Human Rights Commission, elaborado pelo canadense John Humphrey, possivelmente assistido por René Cassin, em junho de 1947, previa um único artigo: "35. Everyone has the right to participate in the cultural life of the community, to enjoy the arts and to share in the benefits of science." ${ }^{12} \mathrm{O}$ projeto final da Comissão substituiu as duas últimas palavras pelo seguinte: "that result from scientific recoveries." 43 Embora um primeiro grupo de trabalho tenha elaborado uma convenção apenas para direitos civis, o segundo grupo de trabalho incluía um subtítulo "Social, Economic and Cultural Rights", precedido pela disposição anterior (número 35) por um "Right to education" (art. 31), uma disposição sobre os

\footnotetext{
$42 \mathrm{E} / \mathrm{CN} .4$ / AC 1./3.

43 Disponível em: http://www.un.org/en/ga/search/view_doc.asp?symbol=E/CN.4/36/ADD.2. Somente o direito à educação foi incluído no primeiro projeto E / CN.4 / 2 "Projeto de Declaração dos Direitos e Deveres Internacionais do Homem / formulado pela Comissão Jurídica Interamericana: 01/08/1947”. Em contrapartida, o projeto dos Estados Unidos de 26.11.1947 (E / CN.4 / 36) previsto no art. 9: "Todo mundo tem direito a uma vida decente; trabalhar e promover seu bem-estar; saúde, educação e previdência social. Serão oportunidades iguais para todos participarem da vida econômica e cultural da comunidade."
} 
objetivos da educação universal (art. 31 A), "right to rest and leisure" (art. 32), direito à seguridade social (art. 33) e direito à saúde (art. 34). Outro artigo subsequente, baseado no segundo parágrafo do artigo 27 da DUDH, garantiu que os autores de obras artísticas, literárias e científicas e inventores "shall retain in addition to the just remuneration of their work a moral right on their work and/or discovery, which shall not disappear, even after such work shall have become the common property of mankind." (Art. 35 A). Finalmente, após uma garantia mais limitada dos direitos das minorias do que a contida no texto de primeiro de junho:

36. In States inhabited by a substantial number of persons of a race, language or religion other than those of the population, persons belonging to such ethnic, linguistic or religious minorities shall have the right, as far as compatible with public order, to establish and maintain schools and cultural or religious institutions, and to use their own language in the press, in public assembly and before the courts and other authorities of the State. ${ }^{44}$

Do trabalho inicial, deduz-se que a noção de direitos culturais não era predefinida e não se distinguia muito bem da de direitos econômicos e sociais, uma vez que aparentemente se referia a atividades, bens e serviços com valores e direitos intangíveis (morais) próximos aos das minorias.

trabalho preparatório revela profundas divergências, ${ }^{45}$ também evidenciadas pela Declaração Americana de 1948, preparada pouco antes do final do trabalho, que incluía a fórmula do direito de participar da vida cultural (art. 13), mas não a garantir cláusula das minorias, mas estabelecendo em seu preâmbulo o dever de "to practice and foster culter by every means." 46 No final dos trabalhos preparatórios na ONU, o direito de participar da vida cultural como um mínimo comum denominador foi incluído no art. 27 da DUDH (com reserva da França) e aplicada pelo art. 15 do PIDESC (Pacto Internacional sobre Direitos Econômicos, Sociais e Culturais), com garantias adicionais de não discriminação (nos parágrafos 2 e 3 do artigo 2 do PIDESC), enquanto o direito à educação das crianças e a cláusula de A proteção das minorias foi recuperada pelo art. 27 do PIDCP (Pacto Internacional sobre Direitos Civis e Políticos).

Pouco se sabe sobre a origem do termo "vida cultural". Não aparece no Estatuto da UNESCO de 1945, que parecia atribuir uma função residual ao conceito de cultura, definindo como finalidade da Organização a cooperação internacional "through education, science and culture" (art. 1), identificando no preâmbulo um "wide diffusion of culture", um dever sagrado das nações combinado com um objetivo educacional individual: "a truer and more perfect knowledge of each other's lives".

\footnotetext{
${ }^{44}$ E / CN.4 / 57. Em alternativa a esta versão, offerta só come "suggerimento" ai governi, se contiver uma proposição restritiva, restritiva ao sujeito do espírito do minoranze.

${ }^{45}$ Cf. E. Stamatopoulos, Direitos culturais no direito internacional, Dordrecht 2007, 11ss.; mais em geral da final C. Roberts, A História Contenciosa da Carta Internacional de Direitos Humanos, Cambridge 2016.

46 "Na medida em que o desenvolvimento espiritual é o supremo fim da existência humana e a mais alta expressão dela, é dever do homem servir esse fim com toda a sua força e recursos. Uma vez que a cultura é a mais alta expressão social e histórica desse desenvolvimento espiritual, é dever do homem preservar, praticar e promover a cultura por todos os meios ao seu alcance. E, como a conduta moral constitui o florescimento mais nobre da cultura, é dever de todo homem sempre respeitá-la."
} 
Tampouco estava contido no Estatuto da Liga das Nações, que se limitou a reconhecer as colônias como um "princípio" segundo o qual "o bem-estar e o desenvolvimento de tais povos são uma tarefa sagrada da civilização" (art. 22). O Tratado de 28 de junho de 1919, celebrado pelas principais potências aliadas e associado à Polônia, estabeleceu como uma "lei fundamental" a obrigação de proteger "a vida e a liberdade sem distinção de nascimento, nacionalidade, idioma, raça e raça, religião" (art. 2). A Carta das Nações Unidas, em particular no capítulo sobre cooperação econômica e social, estabelece os objetivos de "higher standards of life", juntamente com a "international cultural and educational cooperation" e a proteção dos direitos humanos (art. 55)

"Kulturleben", "cultural life", "vie culturelle", "vida cultural" era um conceito com um precedente do século XIX, que surgiu não apenas nas publicações da resistência judaica, mas também antes nas ciências primitivas - também legais $-{ }^{47}$ da cultura do início do século $X X{ }^{48} \mathrm{O}$ chamado à vida adquiriria um significado particular no período pós-guerra. Raphael Lemkin instou desde 1933 a punir como crime internacional atos de vandalismo direcionados contra a "cultura mundial", mas a Convenção contra o Genocídio não havia aceitado sua proposta de incluir também atos de aniquilação cultural nesse crime. ${ }^{49}$ A declaração African Claims in South Africa de 1943 não usava esse termo, mas exigia a abolição da "policy of segregation in all aspects of our national life", uma política baseada na discriminação de raça e cor.

O conceito de "vida cultural" já havia sido usado por algumas das constituições vigentes naquela época e objeto de estudos encomendados pela Comissão, contextos talvez até agora negligenciados pelas interpretações da DUDH. ${ }^{50}$ A Constituição Soviética de 1936 garantiu "a constante elevação do nível cultural dos trabalhadores" (art. 11) e os direitos iguais dos cidadãos em todos os campos da "vida econômica, estatal, cultural, social e política, independentemente da nacionalidade e raça." (art. 123). Em 1937, a Constituição irlandesa respondeu "The Irish nation hereby affirms its inalienable, indefeasible, and sovereign right to choose its own form of Government, to determine its relations with other nations, and to develop its life, political, economic and cultural, in accordance with its own genius and traditions."

\footnotetext{
${ }_{47}$ Por exemplo, K.-J. Seitz, Biologie des geschichtlich positived Rechtes im Kulturleben der Gegenwart, Leipzig 1906.

${ }^{48}$ Cfr. Destruição alemã da vida cultural na Polônia, Nova York: Polish Information Center, [ca. 1940]; Synthese: uma revista internacional de epistemologia, metodologia e filosofia da ciência dedicada à vida cultural e científica atual, Dordrecht 1936; E. Ben-David, Gli ebrei nella vita culturale italiano: 1848-1928, Città di Castello, 1931; T. Čapek, Os Čechs (boêmios) na América: um estudo de sua vida nacional, cultural, política, social, econômica e religiosa, Boston, 1920; S. Debré, Considerações ao sul dos principais estágios da vida cultural israelense, suivies d'un recueil de prières, sd, 1900; K. Schmidt, Die Geschichte der Pädagogik: in weltgeschichtlicher Entwicklung und im organischen Zusammenhange mit dem Culturleben der Völker, Cöthen, 1860; F. Körner, Die Bedeutung der Realschulen für das moderne Kulturleben, Leipzig 1851.

${ }^{49}$ Cfr. Sentença Krstic della Corte Internazionale for l'Ex-Jugoslavia. Disponível em: http://www.icty.org/x/cases/krstic/ tjug/en/krs-tj010802e-3.htm.

50 Valeria a pena investigar as garantias direitos culturais individuais nas constituições do século XIX. O primeiro rascunho de uma lei fundamental do Império Alemão de 26. 4. 1848, por exemplo, previa uma "liberdade de desenvolvimento do folclore (volksthümlich), em particular de raças não-germânicas, equiparando a linguagem em relação à educação. e administração interna."
} 
As primeiras declarações de direitos culturais foram desenvolvidas pelas constituições nacionais elaboradas entre 1945 e 1947. A Constituição da Indonésia de 1945 dedicou um capítulo inteiro à educação e cultura, o primeiro destinado a "elevar a vida nacional" e, através de uma combinação de ciência e tecnologia com sentimentos religiosos, para "promover a civilização" (art. 31), o segundo baseado na responsabilidade do Estado pelo progresso da cultura nacional e pela garantia da liberdade cultural dos povos e idiomas das regiões: "The state shall advance Indonesia's national culture among the civilizations of the world by guaranteeing the freedom of the people to maintain and develop cultural values." (art. 32). A Constituição brasileira de 1946 acrescentou a liberdade da ciência, da literatura, das artes e o dever de proteger a cultura: "Art. 174 - O amparo à cultura e dever do Estado." O artigo 25 da Constituição japonesa (1946) declarou: "All people shall have the right to maintain the minimum standards of wholesome and cultured living." O preâmbulo da Constituição francesa (1946) garantia "igual acesso de crianças e adultos à educação, formação profissional e cultura". A Constituição iugoslava (1946) garante o desenvolvimento cultural das minorias (art. 13), o trabalho cultural (art. 31), o desenvolvimento e a promoção da cultura popular (art. 37 e 38), o acesso às instituições cultura cultural (art. 41) e cultura física (art. 44). As constituições regionais alemãs anteriores à Lei Fundamental também dedicaram seções especiais à educação escolar e cultural (Baviera, Hesse 1946) e ao "cuidado da cultura" (Renânia-Palatinado, 1947). Last, but not least, a Constituição italiana (1947) atribuiu à cultura a classificação de princípio constitucional fundamental, delegando à República a promoção do "desenvolvimento da cultura e da pesquisa científica e técnica, bem como a proteção da paisagem e do patrimônio histórico e artístico da nação." (art. 9). Este princípio fundamental inspira não apenas a estrutura da República, em particular o pluralismo das autoridades locais, mas também os direitos inerentes às relações "ético-sociais", os direitos socioculturais que precedem o socioeconômico e incluem garantias de instituições como família, escola, universidade, etc.

Também à luz desses textos, a invenção da categoria de direitos culturais, ${ }^{51}$ com direito à educação e direito geral e residual, de "participar da vida cultural", 52 parece ter ocorrido simultaneamente no Direito Internacional e Constitucional do século passado. Não foi uma

\footnotetext{
51 Ver PY Chow, Direitos culturais no direito e no discurso internacionais: desafios contemporâneos e perspectivas interdisciplinares, Leiden 2018; L. Belder, H. Porsdam (orgs.), Negociating Cultural Rights, Londres, 2017; A. Jakubowski (ed.), Direitos culturais como direitos coletivos: uma perspectiva do direito internacional, Leiden, 2016; S. Borelli, F. Lenzerini (eds.), Patrimônio Cultural, Direitos Culturais, Diversidade Cultural: Novos Desenvolvimentos em Direito Internacional, Leiden, 2012; L. Reidel, O que são direitos culturais? Protegendo grupos com direitos individuais, Journal of Human Rights 2010, 65ss; F. Francioni (ed.), Direitos humanos culturais, Leiden 2008; E. Stamatopoulos, Direitos Culturais em Direito Internacional, Boston 2007; S. Marks, Definindo Direitos Culturais, em: M. Bergamo (ed.), Direitos Humanos e Justiça Criminal para os oprimidos, Leiden 2003, 293ss; J. Symonides, Direitos Culturais, in: id. (ed.), Direitos Humanos: Conceito e Padrões, Ashgate, 2000, 175ss; H. Niec, Direitos Culturais e Erros, Leicester 1998; C. Lury, Direitos culturais: tecnologia, legalidade e personalidade, Londres 1993.

${ }^{52}$ Cf., na doutrina, M. Ferri, A Evolução do Diretório de Participar da Vida Cultural e do Concelho de Direção Cultural no Diretório Internacional, La Comunità Internazionale 2014, 211ss; M. Odello, O Direito de Participar da Vida Cultural, Anuário Espanhol de Direito Internacional 2011, 493ss; C. Groni, Das Menschenrecht a Teilnahme am Kulturellen Leben: Inhalt, Grenzen e Justitiabilität do Art. 15 (1) lit. A) dos países internacionais Paktes über wirtschaftliche, Soziale and Kulturelle Rechte, Stuttgart 2008; Y. Donders, O Marco Legal do Direito de Participar na Vida Cultural, em: id., V. Volodin (eds.), Direitos humanos na educação, ciência e cultura: desenvolvimentos legais e desafios, Paris: Unesco 2007, 231 ss; R.
} 
simples concessão à utopia socialista da época destinada a ser erradicada em 1989, nem um cavalo de Tróia destinado a justificar derrogações e violações específicas ou a favor de um relativismo cultural que ameaçava o universalismo dos direitos humanos e a soberania dos Estados. Ao contrário, fazia parte da visão de uma nova ordem mundial com novos Estados constitucionais, diferentes e em evolução, mas comunicando e cooperando mesmo sem nenhuma reivindicação de homogeneização.

\section{Fontes fragmentadas e interpretação evolutiva sistemática dos direitos culturais fundamentais}

Nos últimos setenta anos, uma interpretação internacional dos direitos culturais fundamentais foi desenvolvida no âmbito da ONU e da UNESCO e nas Organizações Regionais de Direito Internacional, bem como uma pluralidade de interpretações constitucionais nas instituições existentes nos níveis nacional, regional e local; um sistema complexo de garantias e defesas que exigiria um estudo comparativo mais profundo.

Em relação a fontes internacionais, ${ }^{53}$ as Nações Unidas adotaram pela primeira vez a Convenção de Haia para a proteção de bens culturais em caso de conflito armado (1954) e, depois dos dois acordos gerais, uma série de outras cláusulas de tratados especiais (art. 13 da Convenção sobre a Eliminação de Todas as Formas de Discriminação contra as Mulheres; art. 31 da Convenção sobre os Direitos da Criança, art. 5 da Convenção sobre a Eliminação de Todas as Formas sobre discriminação racial, artigos 31, 43 da Convenção Internacional para a Proteção dos Direitos dos Trabalhadores Migrantes e de suas Famílias) e, mais recentemente, a Declaração das Nações Unidas sobre os Direitos dos Povos Indígenas - UNDRIP (2007), enquanto a Comissão de Direitos Econômicos, Sociais e Culturais preparou os Comentários Gerais no. 13 sobre o direito à educação (1999), n. 17 sobre direitos autorais (2005) e n. 21 sobre o direito de participar da vida cultural (2009). A UNESCO adotou primeiro instrumentos para a proteção do patrimônio cultural, ${ }^{54}$ no novo século, a Declaração Universal da Diversidade Cultural (2001) e depois a Convenção para a Proteção e Promoção da Diversidade das Expressões Culturais (2005).

\footnotetext{
O'Keefe, O Direito de Participar da Vida Cultural, nos termos do Art. 15, Direito Internacional e Comparativo, quarto trimestre de 1998.

53 Cf. finalmente G. Cavaggion, Diritti culturali e modello costituzionale di integrazione, Torino 2018, 40ss.

${ }^{54}$ Convenção sobre medidas a serem adotadas para proibir e impedir a importação, exportação e transferência de bens ilícitos de bens culturais (1970), não absorvida, mas substituída pela Convenção da UNIDROIT sobre bens culturais roubados ou exportados ilegalmente ( 1995); a Convenção para a Proteção do Patrimônio Mundial Cultural e Natural (1972), a Convenção para a Proteção do Patrimônio Cultural Subaquático (2001) e a Convenção para a Proteção do Patrimônio Cultural Imaterial (2003). Para soft law, veja, por exemplo, a Carta Internacional para a Proteção das Cidades Históricas (1987), promovida pelo Conselho Internacional de Monumentos e Sítios (ICOMOS).
} 
No nível internacional regional, o Conselho da Europa também desenvolveu numerosas convenções para a proteção do patrimônio cultural..$^{55}$ Também entrou em vigor a Convenção para a Proteção das Línguas Regionais e Minoritárias (1992), o Convenio para a Proteção das Minorias Nacionais (1995) e a Convenção de Faro sobre o Valor do Patrimônio Cultural para a Sociedade ( 2005), que ainda não foi ratificado pela Itália, enquanto que em 1996 a tentativa de desenvolver um protocolo adicional à Convenção Europeia para a Proteção dos Direitos Humanos e das Liberdades Fundamentais sobre direitos culturais foi suspensa indefinidamente; A Carta Social Europeia também aplica o artigo 26, em vez do artigo 27 da DUDH. ${ }^{56}$ Por seu lado, a União Europeia "respeitará a riqueza de sua diversidade cultural e linguística e garantirá a conservação e o desenvolvimento do patrimônio cultural europeu." (art. 3.3 do TUE).

Também existem instrumentos regionais nas Américas, começando com a Convenção sobre a Proteção do Patrimônio Arqueológico, Histórico e Artístico das Nações Unidas (1976) e a Convenção Americana de Direitos Humanos, que protegeu os direitos coletivos à terra dos povos indígenas. ${ }^{57}$ Os artigos 22 e 27 da Carta Africana dos Direitos Humanos e dos Povos (1981) garantem o direito ao seu próprio desenvolvimento cultural e o dever de "preservar e fortalecer valores africanos positivos", sendo complementado por uma Carta para o Renascimento Cultural Africano (2006). A Carta Árabe de Direitos Humanos (2004) obriga os Estados a "erradication of illiteracy" (art. 41) e a cooperar em programas recreativos, culturais, artísticos e científicos "with the full participation of intellectuals and inventors and their organisations." (art. 42). Após a primeira Declaração do Patrimônio Cultural (2000), a Declaração dos Direitos Humanos da Associação das Nações do Sudeste Asiático (2012) reproduz os direitos culturais declarados pela DUDH, acrescentando como objetivos educacionais o senso de dignidade e participação eficaz na própria sociedade e, como concretização do ideal de harmonia, "understanding, tolerance and friendship among all nations, racial and religious groups." (art. 31).

Apesar da pesquisa da Häberliana, a disseminação dos direitos culturais e sua interpretação nas fontes constitucionais estaduais e regionais mais recentes são menos estudadas. $\bigcirc$ substantivo ou adjetivo está agora nas 145 e 172 das 200 constituições, um "right to culture" em 158 (em um sentido muito amplo, incluindo apenas as obrigações do Estado), um "right to cultural life" em 50, 58

\footnotetext{
55 Convenção Cultural Europeia (1954), Convenção para a Proteção do Patrimônio Arqueológico (1969), Convenção sobre Violações do Patrimônio Cultural (1985: não em vigor), Convenção para a Proteção do Patrimônio Arquitetônico da Europa (Granada 1985). ), Convenção Europeia da Paisagem (2000), a UNIDROIT promoveu a adoção da Convenção sobre o Retorno Internacional de Bens Culturais Roubados ou Exportados Ilegalmente, assinada em Roma em 24 de junho de 1995 (ratificada pela Itália pela Lei 213 de 7 de Junho de 1999 e agora mencionado no artigo 87 do Código de Propriedade Cultural).

${ }^{56}$ Em 1952, o direito à educação foi adicionado à CEDH. A CSE de 1961 garante o direito à orientação e treinamento vocacional (art. 9, 10), enquanto a CSE de 1996 também garante educação primária e secundária gratuita para crianças e adolescentes (art. 17) e creches (art. .27). Cfr. M. Miccola, Direitos Humanos Sociais da Europa, Karelactio 2010, 604ss.

57 Corte Interamericana de Direitos Humanos, Comunidade Mayagna (Sumo) Awas Tingni v. Nicarágua, 31. 8. 2001. Cfr. S. Wiessner, Os direitos culturais dos povos indígenas: conquistas e desafios contínuos, European Journal of International law 2011, 121 e segs.

${ }^{58}$ Disponível em: https://www.constituteproject.org/search?lang=pt\&key=cultrght\&status=in_force\&status=is_draft.
} 
uma referência à "identidade cultural" em 20. ${ }^{59}$ Um interesse especial foi registrado, por exemplo, no debate asiático sobre multiculturalismo mencionado no artigo 10 da Constituição de Taiwan desde $1997^{60}$ e na reforma constitucional do Quênia. ${ }^{61}$

Finalmente, fontes jurisprudenciais e contribuições da doutrina também são mais difíceis de avaliar. Na jurisprudência do primeiro Permanent International Court of Justice e do atual Tribunal Internacional de Justiça, por exemplo, não apenas o indivíduo tem o direito de escolher se deseja pertencer a uma minoria ou não (direito das minorias na Alta Silésia, 1928) ou o direito da minoria de preservar suas tradições (Comunidade Grego-Búlgara, 1930), mas também o direito de levar um modo de vida nômade (Disputa de fronteira Burkina Faso / disputa do Níger 2013). ${ }^{62}$ Na jurisprudência do Tribunal Europeu de Direitos Humanos, parece emergir o novo direito a uma "identidade cultural" com um forte potencial impetuoso; na Declaração de Friburgo (2007), esse direito era antes mesmo do direito à cultura, entendido como o direito de participar da vida cultural na arte. 27 DUDH. ${ }^{63} \mathrm{O}$ último relatório do "Special Rapporteur in the Field of Cultural Rights", Karima Bennoune, em 2018,64 interpretou o último como "the right of each person to freely choose and have cultural references and to identify with multiple and simultaneous cultural groups or none, to participate in cultural life and to be able to change their choices and exit groups."

A fragmentação de fontes legais de direitos culturais não contradiz sua natureza jurídica, porque o princípio do pluralismo cultural também promove pluralismo jurídico. Um estudo recente sobre as práticas de quatro organizações de direitos humanos das Nações Unidas ${ }^{65}$ mostrou que é

\footnotetext{
59 Cfr. por exemplo art. 30 custo Bolívia 2009: "I. Uma nação e um povo indígena rural consiste em todo coletivo humano que compartilha uma identidade cultural, idioma, tradição histórica, instituições, território e visão de mundo, cuja existência é anterior à invasão colonial espanhola. [...] II. No âmbito da unidade do Estado, e de acordo com esta Constituição, as nações e os povos indígenas rurais gozam dos seguintes direitos: [...] 2. À identidade cultural, crenças religiosas, espiritualidades, práticas e costumes, e seus direitos. própria visão de mundo. 3. Que a identidade cultural de cada membro, se assim o desejar, seja inscrita junto com a cidadania boliviana em sua carteira de identidade, passaporte e outros documentos de identificação com validade legal."

${ }^{60}$ Li-Jung Wang, Rumo à cidadania culturale Direitos culturais e política cultural em Taiwan, Cidadania 2013, 92ss.; W, Kymlicka, Multiculturalismo liberal: modelos ocidentais, tendências globais e debates asiáticos, em: id., B. He (eds.), Multiculturalismo na Ásia, Oxford 2005, 22ss.

${ }^{61}$ Cf. Finalmente, o julgamento da Corte Africana de Direitos Humanos declarando que a República do Quênia violou os direitos dos indígenas Ogiek, ACtHPR, Pedido 006/2012 (2017) e L. Hugues, M Lamont, Direitos Culturais e Mudança Constitucional, African Studies 2018, 159ss.; H. Deakcon, Entendendo o trabalho que a 'cultura' faz: Uma perspectiva comparativa sobre os direitos culturais na Constituição do Quênia 20110, African studies 2018, 171aa.

${ }^{62}$ E. Polymenopoulou, Direitos Culturais na Jurisprudência do Tribunal Internacional de Justiça Leiden Journal of International Law 2014, 447ss.

${ }^{63}$ Art. 3 (identidade e patrimônio cultural) "Todos, sozinhos ou em comum, têm o direito de: a. Escolher e respeitar sua própria identidade cultural na diversidade de seus modos de expressão [...]" CEDH, Chapman v. UK n 27238/95, CEDH 2001-I: "O Tribunal considera que a ocupação de sua caravana pela recorrente é parte integrante de sua identidade étnica como cigana, refletindo a longa tradição dessa minoria em seguir uma estilo de vida itinerante." Adere ao exposto, por exemplo, M. Ferri, op. cit., 228ss.

${ }^{64}$ Assembleia Geral da ONU, A /.

65 73/227H. Arsheim, Legalidades não vinculadas? Journal of Law, Religião e Estado 2019, 57ss.
} 
dada atenção especial a fontes religiosas e costumeiras, ou seja, a fontes não estatais, entre as quais se pode encontrar fontes corporativas produzidas pela ética nos negócios. ${ }^{66}$

A partir da evolução do quadro geral das fontes legais de direitos culturais fundamentais no período pós-guerra, apenas algumas conclusões gerais podem ser tiradas aqui para uma interpretação sistemática e evolutiva do conceito de "cultura" subjacente aos direitos culturais fundamentais:

(1) Os direitos culturais são um tipo de direitos humanos distintos dos direitos econômicos e sociais, mas têm em comum o fato de terem sido desenvolvidos separadamente dos direitos civis e políticos porque exigem ações concretas dos Estados e sua cooperação internacional. Eles são direitos humanos individuais, referidos não apenas à pessoa que se distingue dos outros, mas também ao indivíduo entendido como um "animal social" que se une - ou seja, os direitos dos indivíduos integrados nas comunidades, talvez até nas comunidades simbiótica entre seres humanos e outras formas de vida-, ${ }^{67}$ direitos cuja titularidade também pode pertencer a comunidades, mas não a estados ou organizações infranacionais ou internacionais, que ao invés disso são dotadas de supremacia. Do ponto de vista subjetivo, esses direitos podem não constituir uma cosmópolis, mas pelo menos uma família da humanidade composta de nações, povos, comunidades linguísticas e religiosas, associações e "estados gerais", famílias e clãs, isto é, de formações sociais que têm em comum o fato de que todas são, em última instância, minorias.

(2) O exercício de outros direitos fundamentais para fins culturais não os transforma em direitos culturais, mas não proíbe a dupla qualificação. A liberdade de imprensa, por exemplo, pode atuar como um direito civil, econômico e cultural e garante a liberdade de vida privada, pensamento, consciência e religião, expressão e associação (arts. 8, 9, 10 e 11 da CEDH) permitiram aos juízes de Estrasburgo criar direitos culturais derivados de direitos humanos fundamentais e outros direitos de personalidade. ${ }^{68}$ Por outro lado, alguns direitos culturais, como o direito à educação, o direito autoral e o direito à identidade, também foram reconhecidos como direitos civis ou econômicos subjetivos, diretamente justificáveis. A "civilização" impressa no adjetivo de direitos civis denota finalmente uma ideia ou valor concebível como "benefício cultural".

(3) A cultura objeto dos direitos culturais humanos não é puro espírito divino, nem é simplesmente a qualidade imaterial dos bens, como se pensava no direito humanitário, mas também inclui estilos e modos de vida. Na vida humana, tornou-se um fenômeno perceptível, explicável e avaliável de ação, criação, provisão, interpretação, participação, comunicação de sujeitos; dinâmica

\footnotetext{
${ }^{66}$ Cfr. o Conselho Econômico e Social da ONU E / C.12 / GC / 24, Comitê de Direitos Econômicos, Sociais e Culturais Comentário geral nº 24 (2017) sobre as obrigações do Estado sob o Pacto Internacional sobre Direitos Econômicos, Sociais e Culturais no contexto de atividades de negócios.

${ }^{67}$ Pode haver aldeias ou sociedades de abelhas, formigas, leões e raposas, mas neste caso não estamos falando de culturas, mas de "culturas" do homem. Para direitos sobre rios e florestas, veja os julgamentos da Apex da Índia no caso Mohd. Salim v. State of Uttarakhand 20. 3. 2017 e della Court costituzionale della Colombia no caso fiume Atrato de 10. 11. 2016, T-622/2016. Mais amplamente, R. Miguez Nunez, le avventure del soggetto, Milano 2018, 110ss.

${ }^{68}$ Cfr.Conselho da Europa, Tribunal Europeu dos Direitos do Homem, direitos culturais na jurisprudência do Tribunal Europeu dos Direitos do Homem, Estrasburgo 2011. Disponível em: https://www.echr.coe.int/Documents/Research_ report_cultural_rights_ENG.pdf.
} 
que reproduz e altera julgamentos de significado e valor nas comunidades. A vitalidade de uma cultura que não é mais concebida como estática e baseada em valores absolutos também começa a ser medida em sua adaptabilidade ao tempo e ao espaço, em termos de sustentabilidade e resiliência. ${ }^{69}$ Exemplares e transferíveis para a cultura são, nesse sentido, os 4 A do direito à educação: Available, Accessible, Acceptable and Adaptable. A elasticidade e a maleabilidade resultantes tornam mais difícil separar a cultura da economia e da política. A economia da cultura e da cultura econômica, mas também as políticas culturais e a cultura política criaram emaranhados e, portanto, podem favorecer monopólios ou oligopólios que ameaçam a separação ou, mais corretamente, a divisão de poderes econômicos, políticos e culturais e suas respectivas formas de pluralismo. Por um lado, os direitos culturais fundamentais não são apenas transversais aos direitos de liberdade do status negativus (sem interferência) e aos direitos de exercer o status positivus (com ações positivas), mas também aos direitos do status activus; por outro lado, correm o risco de não proteger a cultura da lógica da produção e consumo econômico ou da funcionalidade política.

(4) Nem toda vida é cultura, apenas parte da vida é cultura. O conceito de cultura tem, de fato, um significado antitotalitário original e requer uma divisão de esferas ou "campos" (Pierre Bourdieu $\left.{ }^{70}\right)$. Se "participar" da vida cultural significa ser não apenas um shareholder de bens de consumo, mas também um stakeholder dos interesses ligados à atividade, pelo menos uma responsabilidade moral não pode ser deduzida pela manutenção da vida cultural de alguém. A responsabilidade implica a proibição de abandoná-la aos monopólios econômicos ou políticos e o dever de reconhecer seu poder cultural como uma influência no poder econômico e político. Se a vida cultural também pode ser conflituosa, o direito de participar exige garantias processuais de confrontação, se também se deseja um clash com um ruído considerável, mas não violento. Por outro lado, o direito de participar exige garantias organizacionais do pluralismo, entendidas como uma pluralidade de instituições diferentes e independentes e como uma garantia da multi-subjetividade interna das instituições culturais. No que diz respeito ao pluralismo institucional, a cultura deve ser protegida para que não seja monopolizada, por exemplo, por uma religião, partido ou televisão, e para que não seja sujeita a contração excessiva, por exemplo, por os salões de ópera; no que diz respeito à multi-subjetividade interna, formas devem ser garantidas governance inclusiva, por exemplo, por universidades e ciências em diferentes departamentos.

\footnotetext{
${ }^{69}$ Cfr.M. Amari, Manifesto para a Sustentabilidade Cultural, Milão 2012; P. Bilancia (a cura di), Diritti culturali e nuovi modelli di sviluppo. J. Balta Portolés, M. Dragicevic, Sesic, Direitos culturais e sua contribuição para o desenvolvimento sustentável: implicações para a política cultural, International Journal of Cultural Policy 2017, 159 e segs.

70 P. Bourdieu, Le Champs littéraire (1982), Atos da Pesquisa em Ciências Sociais 1991, 3 e segs. Disponível em: https://www. persee.fr/doc/arss_0335-5322_1991_num_89_1_2986.
} 


\section{A pobre arte das garantias legais dos direitos culturais fundamentais}

Os direitos culturais estariam mortos, em vez de vivos, e careceriam de virtualidade jurídica, se só fossem incluídos nas cartas de direitos e administrados por seus fiadores. Na realidade, a proteção legal desses direitos há muito tempo é vista como uma arte pobre; essa consideração é condicionada tanto pela ideia original de que, em primeiro lugar, é necessário um enorme trabalho de educação cívica quanto pela fragmentação das práticas de proteção de direitos individuais. Embora a jurisprudência internacional e constitucional comparada ${ }^{71}$ tenha sido até agora pouco estudada e seja difícil detectar as principais formas de violação dos direitos culturais fundamentais, no novo milênio, pelo menos, os procedimentos de vigilância internacional foram reforçados.

No nível internacional, o Conselho de Direitos Humanos criou em 2009, como parte de seus procedimentos especiais, a figura do "Special Rapporteur in the Field of Cultural Rights", que tem como função identificar as "Best practices de promoção e proteção" dos direitos culturais nos níveis local, nacional, regional e internacional "como" possíveis obstáculos ", fazendo recomendações ao Conselho ou aos Estados (recomendações para cooperação interna ou internacional), bem como estudar a relação entre direitos culturais e diversidade cultural, integrando em particular uma "gender and disabilities perspective". Em 2010, Farida Shaheed, a primeira relatora, revisou o sistema de direitos culturais do Direito Internacional que pode estar sujeito a procedimentos de supervisão:

1. o direito de participar, acessar e contribuir para a vida cultural (Comentário Geral No. 21);

2. o direito de desfrutar dos benefícios do progresso científico (ou acesso à ciência) $;^{72}$

3. liberdade de pesquisa e criação científica (art. 15.3 do PIDESC);

4. liberdade de expressão científica e artística (artes 15.3 do PIDESC e 19.2 do PIDCP);

5. direitos autorais (Comentário geral $\mathrm{n}^{\circ} 17$ );

6. o direito de buscar, receber e fornecer informações (artigo 19.2 do PIDCP);

7. o direito à educação (Comentário geral no 13);

8. direitos culturais à a identidade, idioma, tradições e costumes, patrimônio e território das minorias (Comentário Geral n ${ }^{\circ} 23$ do PIDCP) e dos povos indígenas e tribais; ${ }^{73}$

9. os direitos culturais de participação e o respeito à identidade cultural dos trabalhadores migrantes; ${ }^{74}$

\footnotetext{
${ }^{71}$ Cfr. Finalmente, em relação à ideia do multiculturalismo, G. Cavaggion, Diritti culturali e modello costituzionale di integrazione, Torino 2018, 264ss

72 UNESCO, O direito de aproveitar os benefícios do progresso científico e suas aplicações, Paris, 2009. Disponível em: https://unesdoc.unesco.org/ark:/48223/pf0000185558?posInSet=2\&queryId=N-EXPLORE-649dcff7-0980-48f9-a4ae$6460 \mathrm{~b} 79 \mathrm{c} 3112$.

73 UNDRIP 2007; Convenção da OIT sobre Povos Indígenas e Tribais em Países Independentes, 1989 (n. 169).

${ }^{74}$ Art. 31 Convenção Internacional sobre a Proteção dos Direitos dos Trabalhadores Migrantes e dos Membros de suas Famílias.
} 
10. direito à não discriminação (Comentário Geral nº 20);

11. direito ao descanso e lazer (art. $24 \mathrm{DUDH}){ }^{75}$

O relatório de Karima Bennoune especificou em 2017 que o primeiro direito também inclui acesso e gozo do patrimônio cultural e acesso a formas diversificadas de expressão cultural, liberdade de ciência e arte. ${ }^{76}$ A liberdade de expressão também protegeria as opiniões sobre religião, cultura e tradições que poderiam ser um anátema de acordo com as crenças religiosas ou ideológicas de outros, um pensamento que parece reconhecer a proteção mesmo das culturas leigas. A religião, embora possa estar ligada à identidade das minorias, permanece excluída da cultura que é objeto do relatório, apenas porque existem outros Special Rapporteurs, por exemplo, para liberdade de opinião e expressão, religião, saúde, alimentos, pessoas com deficiência, povos indígenas, migrantes, minorias, racismo e xenofobia, promoção da verdade, justiça, reparação, etc.

Do ponto de vista procedimental, esses direitos culturais podem estar sujeitos não apenas a procedimentos especiais, mas também a procedimentos comuns de reporting y de complaint, ou seja, denúncias individuais ou coletivas, que permitem uma espécie de peer review por representantes estaduais mais ou menos experientes, realizado em reuniões não públicas, ou seja, sem a possibilidade de defender as vítimas e verificar sua eficácia, especialmente em casos de violações graves e estruturais. $^{77}$

Os procedimentos nacionais para relatar os direitos culturais envolvem o Economic and Social Council (ECOSOC) (arts. 16 e segs. Do PIDESC), que estabeleceu, em 1985, o Committee on Economic, Social and Cultural Rights (CESCRC), ocasionalmente também o Human Rights Council (HRC) (art. 40 e segs. ICCPR). Com relação aos procedimentos para a apresentação de reclamações, o Protocolo Adicional do PIDESC (2008) agora permite "comunicações" individuais e coletivas ou de outros Estados por violações de direitos culturais. Além desses procedimentos, existem reclamações ou solicitações individuais permitidas por tratados especiais e endereçadas a órgãos compostos por especialistas independentes, ou seja, procedimentos de supervisão mais técnicos e geralmente sujeitos ao esgotamento das vias processuais internos, e o resultado é divulgado: para as crianças, o Committee on the Rights of the Child (CRC), para as mulheres, o Committee on the Elimination of Discrimination Against Women (CEDAW), para as vítimas do racismo, o Committee on the Elimination of Racial Discrimination (CERD) e para as pessoas com deficiência, o Committee on the Rights of Persons with Disabilities (CDPD). ${ }^{78}$

\footnotetext{
$\overline{75}$ Assembleia Geral da ONU A / HRC / 14/36.

76 Assembleia Geral da ONU A / HRC / 34/56.

77 Uma avaliação positiva, mas sem referência a casos específicos, oferece E. Stamatopoulou, Monitoring Cultural Human Rights, Human Rights Quaterly 2012, 1170ss.

78 O Comitê para a Proteção dos Direitos de Todos os Trabalhadores Migrantes e Membros de suas Famílias (CMW) será responsável pela proteção dos trabalhadores migrantes se a décima ratificação for alcançada.
} 
Um terceiro tipo de mecanismo refere-se à comunicação de casos individuais e coletivos ao Committee on Conventions and Recommendations da UNESCO, órgão composto por representantes políticos e especialistas do Estado, mas não especialistas em direitos humanos. Este comitê é geralmente destinado a determinados trabalhadores no campo da cultura, como professores, estudantes, pesquisadores, artistas, escritores e jornalistas. Os procedimentos são secretos, geralmente sem a presença dos candidatos, e visam principalmente as mediações políticas. ${ }^{79}$

Outros mecanismos atípicos ou mistos estão previstos, por exemplo, no artigo 42 da Declaração das Nações Unidas sobre os Direitos dos Povos Indígenas, que confia ao Permanent Forum on Indigeneous Issues a função de promover o respeito e a plena implementação da Declaração. No entanto, para a Convenção da UNESCO sobre Proteção e Promoção da Diversidade das Expressões Culturais (2005), existe apenas um procedimento para reportar a um comitê intergovernamental e um procedimento de conciliação.

Existem, portanto, vários procedimentos para monitorar os direitos culturais, mas as instituições sociais e culturais de "monitoramento dos direitos culturais" são menos desenvolvidas do que outras formas de Human Rights Watching, talvez nem sempre adequadamente envolvidas nos procedimentos. Além disso, mesmo o relator especial teria dificuldade em reconstruir os resultados da supervisão em um quadro suficientemente significativo dos casos e violações verificadas e sanadas.

Para a questão de qual é o atual "estado da cultura" (state of the culture), a Internet se refere primeiro a um novo programa de entrevistas noturnas nos Estados Unidos e, depois, a dois documentos da UNESCO, o primeiro em 1996 e o último no ano 2000, que tentou estimular o desenvolvimento de um sistema de indicadores de diversidade cultural e iniciar um processo de homogeneização dos direitos culturais. Não apenas pela falta de fundos da UNESCO, abandonados pelos Estados Unidos e agora também por Israel, eles não foram seguidos por outros, mas foram substituídos apenas por instrumentos parciais de auto-observação, como, por exemplo, o World Cities Culture Report.

Apenas as estatísticas sobre a economia cultural permanecem. A vida cultural foi reformulada na UNESCO Culture Cycle, ${ }^{80}$ um ciclo que começa na criação, passa pela produção, disseminação, "exposição / recepção / transmissão" para alcançar "consumo / participação". O Quadro Estatístico Cultural da UNESCO (UNESCO Framework for Cultural Statistics), ${ }^{81}$ revisado em 2009 à luz da Convenção sobre Expressões Culturais de 2007, divide o patrimônio cultural intangível em seis "áreas" essenciais (patrimônio, atividades, visual, livros e artes impressas, mídia audiovisual e interativa, design) e acidentais (turismo, esportes e recreação).

\footnotetext{
79 Y. Donders, Procedimento de Comunicação da UNESCO sobre Direitos Humanos", Amsterdam Law School Studies Paper Research n. 2018-25.

${ }^{80}$ Disponível em: https://image.slidesharecdn.com/ucoloradopresentation12march2012-120312172515-phpapp02/95/ creative-industries-and-the-future-of-universities-12-728.jpg? $\mathrm{cb}=1331573761$.

${ }^{81}$ Disponível em: https://unesdoc.unesco.org/ark:/48223/pf0000191061.
} 


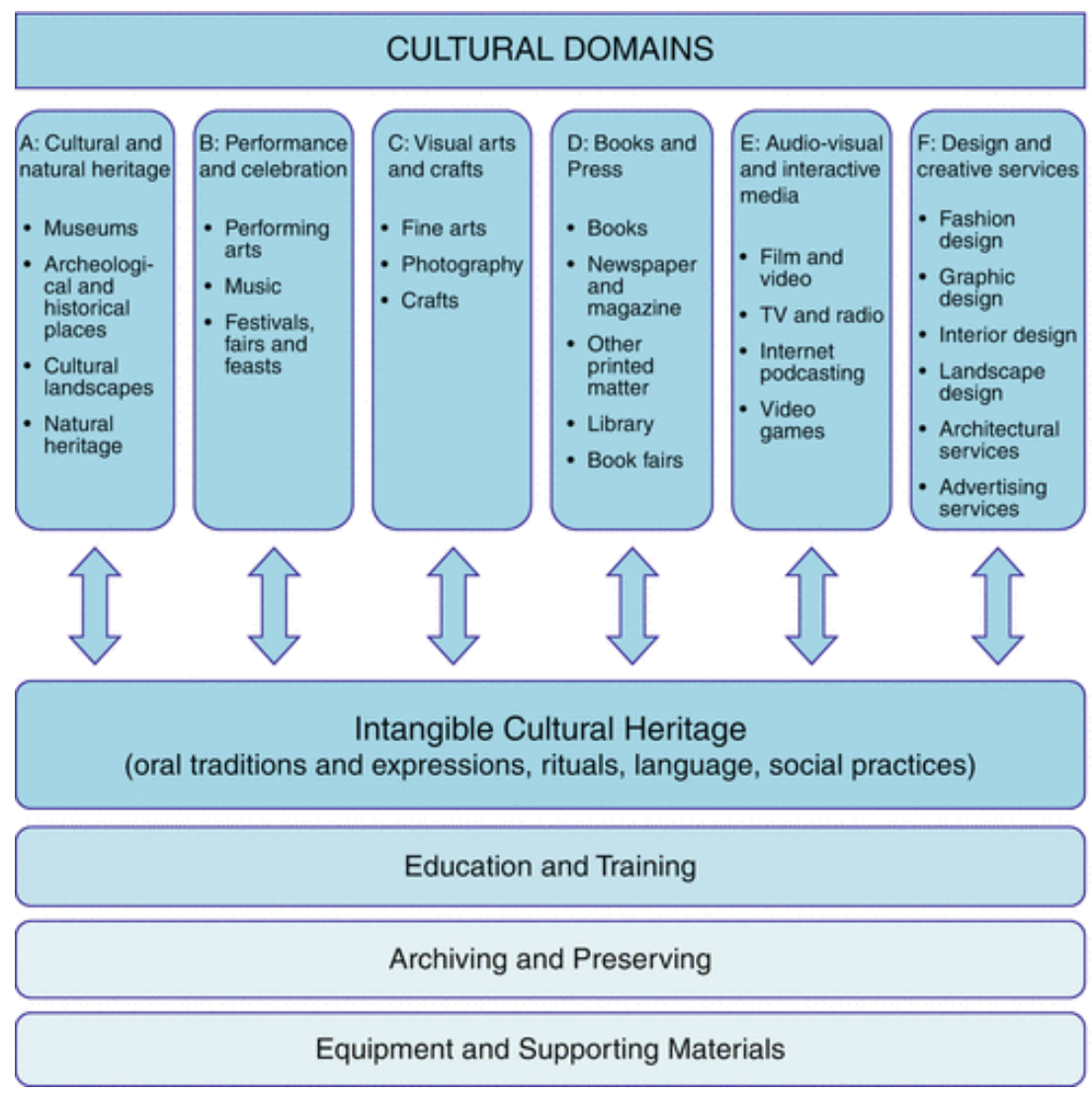

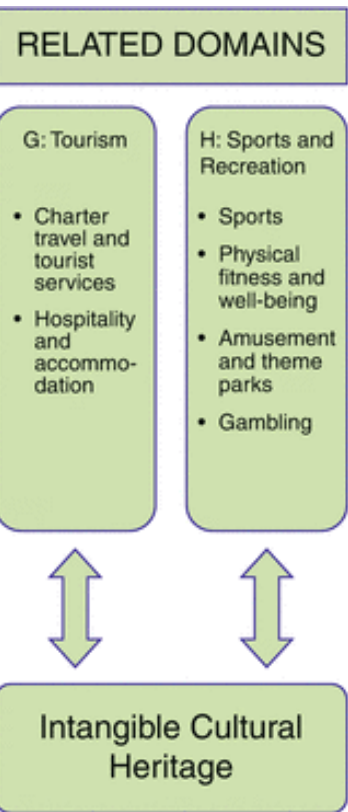

Education and Training

Archiving and preserving

Equipment and Supporting Materials

Nota: As informações constantes no diagrama foram inseridas pelo autor.

Nas estatísticas culturais da União Europeia, ${ }^{82}$ aspectos econômicos, como o número de trabalhadores e empresas que participam da cultura e do comércio exterior de bens culturais, também têm prioridade sobre os indicadores culturais de "participação cultural". Envolve a leitura livros e jornais, assistir a shows de filmes e "life performances" e visitar lugares e instituições culturais, além de usar a Internet para fins culturais. Existem também estatísticas da UE / OCDE / ONU sobre educação e treinamento, ${ }^{83}$ mas não são encontrados dados atuais confiáveis sobre afiliações religiosas. ${ }^{84}$ No entanto, o próprio Eurobarometro 2018 também mostra que o sentido de comunidade ligado à cidadania europeia se baseia mais na "cultura" (29\%), na "história" (23\%) e nos "valores" (23\%) que na "economia" (21\%) ou idiomas (11\%) ou religião (8\%).

\footnotetext{
${ }^{82}$ Estatísticas da cultura, edição de 2016, Bruxelas 2016. Disponível em: https://ec.europa.eu/eurostat/ documents/3217494/7551543/KS-04-15-737-EN-N.pdf/648072f3-63c4-47d8-905a-6fdc742b8605.

${ }^{83}$ Disponível em: https://ec.europa.eu/eurostat/statistics-explained/index.php/Education_and_training_in_the_EU_-_ facts_and_figures.

84 Disponível em: http://www.europe-infos.eu/the-religious-landscape-in-europe (2017).
} 


\section{Os desafios do futuro}

Se você perguntar, em conclusão, qual é o estado atual dos direitos culturais fundamentais, as tendências desde sua invenção e envolvimento em fontes legais até as práticas de proteção descritas acima nos permitiriam ser mais otimistas do que pessimistas sobre o futuro de sua cultura jurídica. No entanto, não devemos esquecer as preocupações com as principais críticas e linhas de conflito que parecem dividir as sociedades na atual fase da globalização, que afeta as gerações de jovens.

As dificuldades de proteger os direitos culturais surgiram especialmente nos momentos conhecidos dos conflitos armados mais recentes, nos quais ocorreu a destruição dos bens culturais. ${ }^{85}$ O otimismo dos anos 90 e o início do novo milênio parece ceder a um pessimismo que afeta tanto o direito quanto a cultura. No que diz respeito ao Direito Internacional e Constitucional, segundo os modelos do constitucionalismo multinível, o espírito da época parece antes diagnosticar uma crise de direitos humanos universais, questionada não apenas por novas teorias críticas, mas também por um niilismo jurídico que dessacraliza as cartas de direitos e combate sem fundamento a religião civil dos direitos fundamentais. Os direitos culturais não apenas não parecem ser invioláveis, mas são, em qualquer caso, o exemplo mais apropriado de direitos vulneráveis, mais abandonados do que reconhecidos. A própria relatora especial lamentou os ataques fundamentalistas, extremistas e terroristas contra artistas e intelectuais, defensores dos direitos da mulher, minorias religiosas e LGBT, professores e estudantes (2017). ${ }^{86}$ Ela considera que o conceito de universalidade é objeto de hostilidade, apesar dos progressos realizados em sua realização, e critica o relativismo cultural pela desconstrução da humanidade em nome de uma cultura. A aplicação dos direitos culturais seria a defesa cultural mais eficaz da universalidade dos direitos fundamentais. ${ }^{87}$

A crise dos direitos humanos também está ocorrendo no contexto de algumas críticas ao Direito Constitucional e Internacional e à justiça. Os críticos da "juristocracy" veem tribunais e juízes que agem sem limites e sem a virtude da modéstia, os soberanos propagam o retorno do unilateralismo e os materialistas reclamam de desigualdades crescentes e irremediáveis. No momento, apenas a crise do rule of law está sendo debatida em relação a vários estados membros da UE, que, além disso, são governados por novos partidos que se opõem ao multiculturalismo. Um estudo recente da Ciência Política sustenta de maneira mais geral que a crise dos direitos fundamentais, particularmente a depreciação da liberdade de associação e expressão, é especialmente grave em democracias imperfeitas devido ao ressurgimento do nacionalismo. ${ }^{88}$

\footnotetext{
${ }^{85}$ Cfr. Seminário intersessional sobre direitos culturais e proteção do patrimônio cultural, Assembleia Geral das Nações Unidas A / HRC37 / 29; S. Chiodi, Beni culturali e conflitti armati. Le sfide ei progetti e M. Carcione, a Blue Shield e a ONG cultural de assistência à miséria de salvaguardia e difusão da Convenção, os Protocolli e delle guidelines of attuazione, em: S. Chiodi, G. Fedeli ( eds.), Beni culturali e conflitti armati, catastrofi naturali and desastri environmenti, Rome 2018, 41 ss e 91 ss.

${ }^{86}$ Assembleia Geral da ONU, A (HRC / 34/56 (2017).

${ }^{87}$ Universalidade, diversidade cultural e direitos culturais, Assembleia Geral da ONU A / $73 / 227$ (2018).

${ }^{88}$ E. Yazici, Nacionalismo e Direitos humanos, pesquisa política trimestral 2019, 147ss.
} 
Quais são as linhas gerais de conflito cultural que podem ser usadas como referência para os direitos culturais fundamentais? Concluindo, só podemos extrair tensões possíveis e levantar algumas questões que podem orientar pesquisas futuras.

(1) $O$ direito e a cultura devem enfrentar novos problemas na produção de falácias e emoções negativas, também por meio das mídias sociais que divulgam fake news y hate speech. Essas novas formas de expressão subcultural também protegem os direitos culturais ou exigem garantias na forma de censura às falsidades e ao ódio contra as comunidades? Na crise do political correctness, os direitos culturais conseguem manter os limites da moralidade nas comunidades políticas existentes? Se a opinião pública europeia e internacional continuar fraca demais para defender as constituições contra os venenos do cinismo, será possível criar um órgão transnacional e procedimentos de autocensura?

(2) Os fenômenos migratórios correm o risco de contrastar populações consideradas "indígenas", embora não minoritárias, com um novo multiculturalismo, percebido como uma ameaça à própria segurança social. Os direitos culturais dos cidadãos podem fingir hospitalidade e prosseguir em defesa cultural da maioria, prevalecendo sobre os de migrantes não nacionais, a quem os deveres culturais são cada vez mais impostos, por exemplo, aprendizado de idiomas e História da cidadania. Quais margens deixam os direitos culturais de ambos para as opções de políticas de migração e integração?

(3) Se a liberdade religiosa também é um direito cultural, a revitalização percebida das religiões pode levar não apenas a uma reversibilidade dos processos de secularização, mas também a uma perda de consenso sobre o valor fundamental da tolerância. Que limites podem então ser impostos às comunidades religiosas em defesa dos direitos culturais de mulheres e crianças, mas também na prevenção da violência motivada por preceitos religiosos? Os privilégios das religiões tradicionais, em nome de igual liberdade religiosa, devem ser concedidos a novas religiões ou a grupos que reivindicam o direito de serem esquecidos por Deus?

(4) Entre populismo e epistocracia, o futuro da democracia tornou-se incerto. Os direitos culturais oferecem um antídoto contra o risco de divinização dos povos, por um lado, e contra sua presunção de ignorância e imaturidade, por outro? $O$ conhecimento dos cidadãos pode ser aprimorado através de consultas, mesmo sem o conhecimento de seus representantes? A educação cívica e a cultura constitucional podem estar sujeitas ao exame de bacharelado?

(5) As inovações nas tecnologias digitais (TIC) e a invenção da inteligência artificial estão revolucionando a sociedade e o Estado. Os direitos culturais, particularmente os direitos autorais, mas também a pesquisa tecnológica e os direitos à privacidade, guiarão e conduzirão essa revolução em direção a novas formas de vida cultural onlife ou colocarão limites e freios em nome da identidade e excepcionalidade pessoais da consciência humana? A inteligência artificial oferecerá espaço a uma ética governada por novos direitos à explicação ou dará espaço a novas guerras cibernéticas? 
Joerg Luther

(6) O consumo do ambiente natural e das mudanças climáticas levará as culturas humanas a salvar ou destruir as bases naturais da vida? Mesmo diante de questões como as mencionadas, o constitucionalista não pode se render ao pessimismo, mas deve manter um mínimo de otimismo moderado de que a humanidade pode lutar contra sua própria natureza para aspirar a "uma constituição civil perfeita (o objetivo final de a cultura)." ${ }^{89}$

${ }^{89}$ I. Kant, Mutmaßlicher Anfang der Menschengeschichte (1786). Disponível em: https://korpora.zim.uni-duisburg-essen. de/kant/aa08/116.html. 